\title{
ATIVIDADE ALELOPÁTICA DA LEUCENA SOBRE ESPÉCIES DE PLANTAS DANINHAS
}

\author{
Nádja de Moura Pires ${ }^{1,3 *}$; Hélio Teixeira Prates ${ }^{1}$; Israel Alexandre Pereira Filho; Rubem Silvério \\ de Oliveira Jr. ${ }^{2}$; Trícia Cristina Lessa de Faria ${ }^{1,3}$ \\ ${ }^{1}$ Embrapa Milho e Sorgo, C.P. 151 - CEP: 35701-970 - Sete Lagoas, MG. \\ ${ }^{2}$ Depto. de Agronomia - UEM, Av. Colombo, 5790 - CEP: 87020-900 - Maringá, PR. \\ ${ }^{3}$ Bolsista CNPq. \\ *Autor correspondente <nadja@cnpms.embrapa.br>
}

\begin{abstract}
RESUMO: Alelopatia é o efeito direto ou indireto de uma planta sobre outra, por meio da produção de compostos químicos liberados no ambiente. Os metabólitos secundários ou produtos naturais envolvidos em alelopatia são denominados aleloquímicos e estão presentes nos tecidos de diferentes partes das plantas. O objetivo deste trabalho foi determinar o potencial alelopático da leucena (Leucaena leucocephala (Lam.) de Wit.) sobre as plantas daninhas Desmodium purpureum (desmódio), Bidens pilosa (picão-preto) e Amaranthus hybridus (caruru). Os bioensaios foram conduzidos em laboratório e em casa de vegetação com extratos aquosos da parte aérea da leucena nas concentrações de 100, $50,25,12,5 \%\left(v^{-1}\right)$. O extrato apresentou maior efeito quando aplicado em papel filtro. O potencial alelopático da leucena variou com a espécie de planta daninha, sendo o picão-preto e o caruru as espécies mais sensíveis ao extrato em ambos os bioensaios. A mimosina foi quantificada por HPLC em concentrações diretamente correlacionadas à concentração do extrato, indicando ser este aleloquímico o provável responsável pelo efeito sobre a germinação e o desenvolvimento das plantas daninhas.
\end{abstract}

Palavras-chave: Desmodium purpureum, Bidens pilosa, Amaranthus hybridus, extrato de planta, mimosina

\section{ALLELOPATHIC ACTIVITY OF LEUCAENA ON WEED SPECIES}

\begin{abstract}
Allelopathy is the direct or indirect effect of one plant on another through substances liberated into the environment, and occurs widely in natural plant communities. The secondary metabolites or natural products involved in allelopathy are called allelochemicals and can be produced in different parts of the plants. The purpose of this study was to determine the allelopathic potential of the aerial part of Leucaena leucocephala on the weeds Desmodium purpureum, Bidens pilosa and Amaranthus hybridus. Bioassays were carried out in laboratory and in greenhouse with aqueous extracts of the aerial part of leucaena in concentrations of $100,50,25,12.5 \%\left(\mathrm{v} \mathrm{v}^{-1}\right)$. The aqueous extract showed major effect over the weeds when applied to filter paper. The allelopathic potential of leucaena varied with weed species, but $B$. pilosa and $A$. hybridus were the most sensible species to the extract in both bioassays. Mimosine was quantified by HPLC in concentrations directly correlated to extract concentrations, indicating this allelochemical as the possible substance involved in effects on weed germination and development.

Key words: Desmodium purpureum, Bidens pilosa, Amaranthus hybridus, plant extract, mimosine
\end{abstract}

\section{INTRODUÇÃO}

A leucena (Leucaena leucocephala (Lam.) de Wit.) é uma leguminosa originária do México, sendo encontrada em toda região tropical (Skerman, 1977). Essa planta apresenta múltiplo potencial de utilização, sendo muito empregada por exemplo no reflorestamento de áreas degradadas, uma vez que melhora as qualidades físicoquímicas e biológicas do solo e como fonte de proteína para alimentação animal, mas neste caso com restrições, devido a presença de substâncias tóxicas nas folhas da leucena (Wee \& Wang, 1987; Weimer, 1998; El-Bedawy et al., 1999). Além disso, Budelman (1988) observou que a cobertura do solo com leucena apresenta propriedades de controle de plantas daninhas e que esse efeito ocorre devido à presença de aleloquímicos na parte aérea da planta.
Estudos realizados por Kuo et al. (1982) mostraram que 0 extrato aquoso das folhas de leucena inibiu o crescimento da radícula de plantas de alface e de arroz. Chou \& Kuo (1986) também observaram que o extrato aquoso das folhas da leucena apresenta fitotoxidade sobre várias plantas e que os aleloquímicos envolvidos nesse efeito são a mimosina ( $\beta$ - $[\mathrm{N}$-(3-hidroxi4-oxopiridil)]- $\alpha$-aminopropiônico), a quercetina, o ácido gálico e os ácidos protecatequico, $p$-hidroxibenzóico, $p$ hidroxifenilacético, vanílico, ferúlico, caféico e p-cumárico. Dentre essas substâncias, o potencial alelopático da leucena é atribuído principalmente ao aleloquímico mimosina (Figura 1), um aminoácido não protéico devido à presença de um grupo hidroxila na posição três e de um oxigênio na posição quatro do anel piridínico (Ward \& Harris, 1976). 


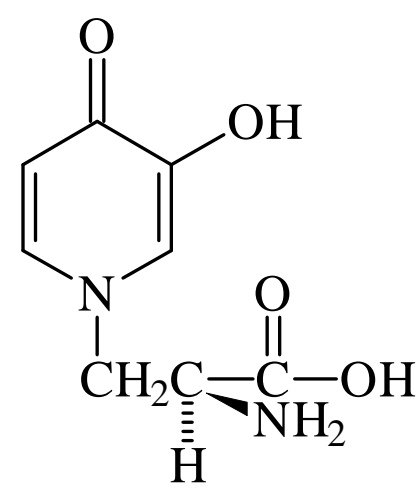

Figura 1 - Estrutura molecular da mimosina, presente em extrato aquoso da parte aérea (folhas e caules jovens) de leucena.

A inibição da germinação e/ou do crescimento de espécies daninhas por efeito alelopático da leucena sugere alternativas de controle de plantas daninhas, não só pelo uso potencial do extrato como um agente químico natural, mas também pela presença de novos grupamentos químicos nas substâncias isoladas nos extratos, as quais podem potencialmente ser manipuladas pela indústria de modo a descobrir novas moléculas com efeito herbicida.

Para constatação do efeito alelopático, o procedimento inicial consiste na técnica do bioensaio, empregando-se material biológico como indicador da ação da substância em estudo (Inderjit \& Dakshini, 1995). O passo seguinte consiste na identificação e quantificação da substância responsável pela atividade, no qual técnicas analíticas mais elaboradas são requeridas (Lowry et al., 1985; Cutler, 1986).

O objetivo deste trabalho foi avaliar em laboratório e em casa de vegetação o efeito do extrato aquoso da leucena sobre a germinação e o desenvolvimento das plantas daninhas desmódio (Desmodium purpureum), picão preto (Bidens pilosa) e caruru (Amaranthus hybridus), bem como quantificar por HPLC a(s) substância(s) responsáveis pelo efeito.

\section{MATERIAL E MÉTODOS}

Obtenção do extrato aquoso de leucena - $O$ extrato foi obtido da parte aérea (folhas e caules jovens) de plantas de leucena com três meses de idade, cultivada em condições de campo. Duzentos gramas da parte aérea foram picados manualmente em pedaços de aproximadamente $2,0 \mathrm{~cm}$ e triturada em liqüidificador (3 ciclos de 15 segundos), com $300 \mathrm{~mL}$ de água à temperatura de $80^{\circ} \mathrm{C}$. Em seguida foram adicionados mais $700 \mathrm{~mL}$ de água a mesma temperatura, para evitar a degradação da mimosina (Lowry et al., 1983), obtendose um extrato de concentração $20 \%(\mathrm{p} / \mathrm{v})$.
Após infusão por 4 minutos, a mistura foi colocada em um funil de Büchner, contendo uma camada de lã de vidro e uma camada de gaze de algodão hidrófilo, sendo então filtrada sob vácuo para obtenção do extrato. $\mathrm{O}$ extrato foi resfriado e armazenado à $10^{\circ} \mathrm{C}$ até o momento de uso.

Bioensaio em laboratório - O bioensaio foi realizado em câmara de incubação, com temperatura de $28^{\circ} \mathrm{C}$ e fotoperíodo de 12 horas. O teste foi realizado em caixas gerbox transparentes de $11 \times 11 \mathrm{~cm}$, forradas com três folhas de papel de filtro, previamente autoclavadas a $120^{\circ} \mathrm{C}$ por uma hora, e umedecidas com $10 \mathrm{~mL}$ do extrato concentrado $(20 \%$ $\mathrm{p} / \mathrm{v}), 100 \%$, e diluído em água nas concentrações de 50, 25 e 12,5\%, utilizando-se água como testemunha (dose zero). Em cada gerbox foram colocadas 10 sementes de desmódio, 20 sementes do picão-preto e 20 sementes de caruru. Os tratamentos foram dispostos em delineamento inteiramente casualizado, com cinco repetições.

Após um período de sete dias avaliou-se a porcentagem de sementes germinadas e comprimento das plântulas. Os valores foram submetidos à análise de variância e regressão. Para descrever a relação entre a resposta da planta $(Y)$ e a dose do extrato $(x)$ foi utilizado o modelo logístico dado pela expressão $Y=a /\left[1+(x / b)^{c}\right]$, em que: $a=$ limite superior; $b=$ dose que inibe metade do crescimento $\left(I_{50}\right) ; c=$ declividade da curva em torno do $I_{50}$.

Bioensaio em casa de vegetação - Este bioensaio foi realizado em casa de vegetação com temperatura máxima de $30^{\circ} \mathrm{C}$ e mínima de $20^{\circ} \mathrm{C}$. As plantas daninhas foram cultivadas em caixas $(47 \times 30 \times 10 \mathrm{~cm})$ contendo um mistura de solo e areia na proporção 1:1. Este substrato foi autoclavado por 1 hora a $120^{\circ} \mathrm{C}$. Em cada caixa foram colocadas 60 sementes de desmódio, 80 sementes de picão preto e 80 sementes de caruru.

Vinte dias após a semeadura, adicionou-se em cada caixa $400 \mathrm{~mL}$ do extrato concentrado $(20 \%(\mathrm{p} / \mathrm{v}))$, $100 \%$, e diluído com água nas concentrações $50,25,12,5$ $\%$, utilizando-se água como testemunha. Os tratamentos para cada espécie foram dispostos em delineamento inteiramente casualizado com três repetições.

Durante a condução do ensaio, manteve-se a umidade das caixas próxima à capacidade de campo. A fitotoxicidade do extrato de leucena sobre as plantas daninhas foi avaliada diariamente, por um período de sete dias, baseando-se na escala de notas do Conselho Europeu de Pesquisa sobre Plantas Daninhas - Ewrc (Frans, 1972), modificada.

Análise do extrato por HPLC - Foi realizada utilizandose a metodologia descrita por Lowry et al. (1985). Empregou-se o cromatógrafo líquido, marca Shimadzu, modelo LC-10A, adaptado com bomba LC-10AD, detetor UV/VIS e injetor de amostra automático. Foi utilizada a técnica do padrão externo, com curva de calibração linear baseada na integração da área do pico pelo método dos mínimos quadrados (curva padrão). 
As condições analíticas empregadas tanto para a curva padrão, quanto para a análise das amostras do extrato foram: fase móvel constituída de solução aquosa de $\mathrm{NH}_{4} \mathrm{H}_{2} \mathrm{PO}_{4} 2 \%$, ajustada para $\mathrm{pH} 2,4$ com $\mathrm{H}_{3} \mathrm{PO}_{4}$, coluna tipo fase reversa $\left(C_{18}\right)$, Shim-pack CLC-ODS(M) com 4,6

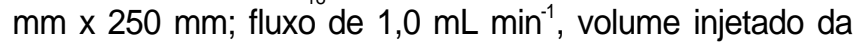
amostra de $20 \mu \mathrm{L}$, comprimento de onda $(\lambda)$ igual a 280 $\mathrm{nm}$. Todas as análises foram feitas em triplicata.

\section{RESULTADOS E DISCUSSÃO}

Bioensaio em laboratório - O modelo logístico descreveu adequadamente a relação entre dose e redução na germinação e comprimento das plântulas das plantas daninhas, sendo que estas características decresceram com o aumento da dose do extrato no papel de filtro (Figura 2). A germinação e o comprimento das plantas daninhas não foram afetados pelo extrato da leucena na
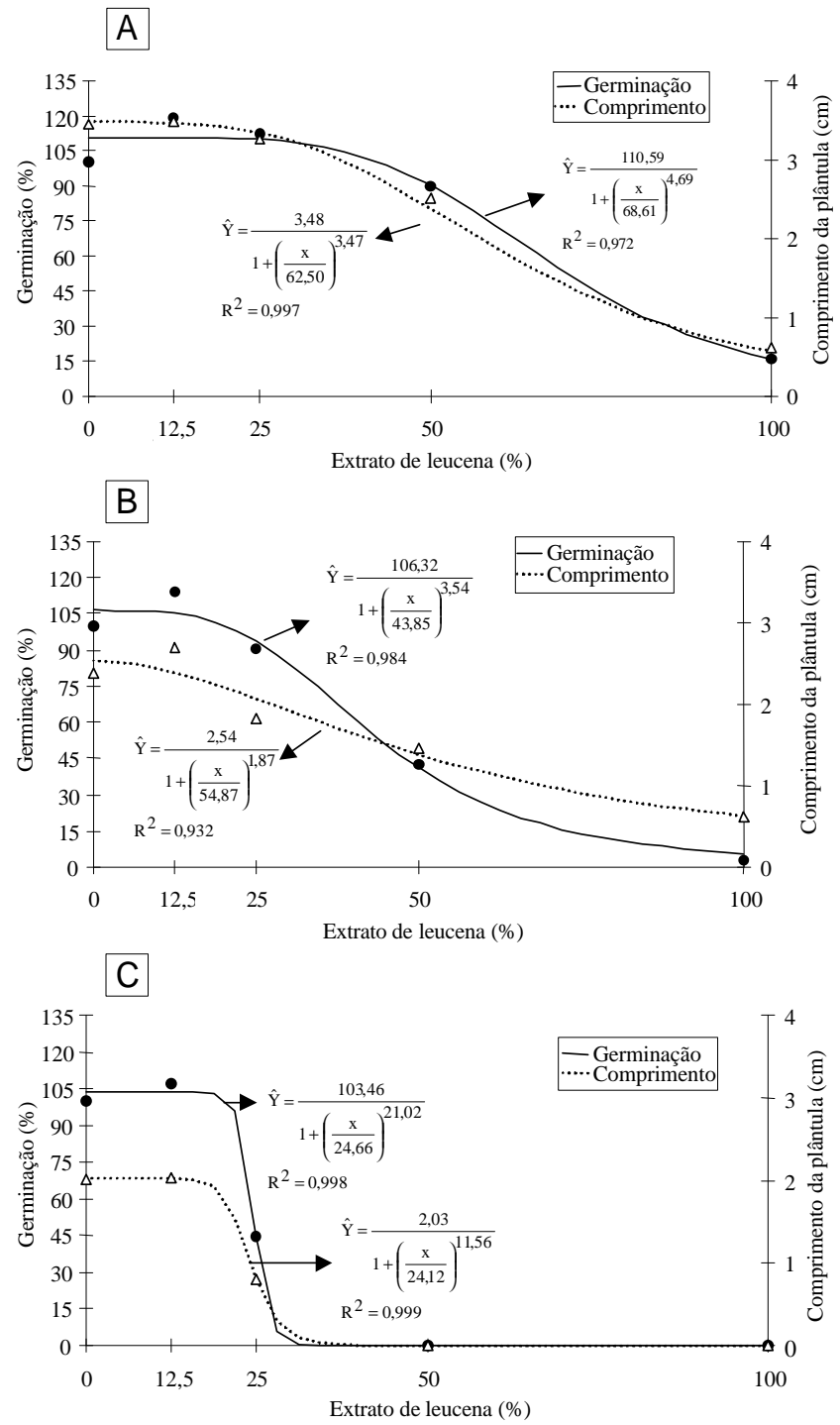

Figura 2 - Germinação de sementes e comprimento das plântulas das plantas daninhas desmódio (a), picão preto (b) e caruru (c), submetidas a doses crescentes do extrato aquoso da parte aérea da leucena. concentração de $12,5 \%$, sendo que a partir dessa concentração o extrato interferiu no desenvolvimento das plantas (Figura 2). De acordo com Jacobi \& Ferreira (1991), a inibição do crescimento da plântula após a germinação, sob o ponto de vista ecológico, é um mecanismo de seleção mais eficiente do que evitar a germinação da planta daninha, porque a descendência é eliminada.

Das plantas daninhas testadas, o desmódio evidenciou menor sensibilidade aos efeitos do extrato (Figura 2). As sementes dessa planta apresentam certa impermeabilidade do tegumento à água, sendo este um dos fatores causadores da dormência observada em sementes desta espécie (Oliveira Jr. \& Delistoianov, 1996). A restrição à absorção de água e soluto poderia explicar o menor efeito do extrato sobre esta espécie, já que as sementes não foram submetidas a nenhum processo de escarificação. A escarificação tem sido adotada para melhorar a germinação do desmódio (Oliveira Jr. \& Delistoianov, 1996; Souza Filho et al., 1997). Das espécies estudadas, o caruru foi mais sensível ao extrato, não se observando germinação nas concentrações de 50 e 100 $\%$, necessitando de uma menor dose do extrato para promover uma redução de $50 \%$ na germinação ou no desenvolvimento das plantas (Figura 2). Estes resultados estão de acordo com os obtidos por Souza Filho et al. (1997), os quais observaram que a leucena apresenta potencial alelopático sobre algumas espécies de plantas daninhas e que este potencial varia com a espécie de planta receptora do extrato.

Bioensaio em casa de vegetação - $\mathrm{Na}$ avaliação da fitotoxicidade sete dias após a aplicação do extrato, as plantas daninhas caruru e picão preto foram mais sensíveis do que o desmódio, verificando-se que o efeito do extrato variou em função das espécies em estudo e das concentrações utilizadas (TABELA 1). As concentrações de 50 e $100 \%$ do extrato foram as mais prejudiciais ao desenvolvimento das plantas, sendo que para o picão preto e caruru estas concentrações induziram a uma redução no crescimento das plantas e à deformação no limbo foliar (Figura 3).

TABELA 1 - Índices de fitotoxicidade, em diferentes plantas daninhas submetidas a doses crescentes do extrato de leucena.

\begin{tabular}{clll}
\hline $\begin{array}{c}\text { Doses do } \\
\text { Extrato }\end{array}$ & \multicolumn{3}{c}{ Fitotoxicidade * $^{*}$} \\
\cline { 2 - 4 } & Desmódio & Picão-preto & Caruru \\
\hline$(\%)$ & & & \\
0 & 1 Nula & 1 Nula & 1 Nula \\
12,5 & 2 Muito leve & 2 Muito leve & 2 Muito leve \\
25,0 & 2 Muito leve & 3 Leve & 3 Leve \\
50,0 & 2 Muito leve & 3 Leve & 4 Média \\
100,0 & 2 Muito leve & 4 Média & 4 Média \\
\hline
\end{tabular}

*Escala EWRC modificada. 

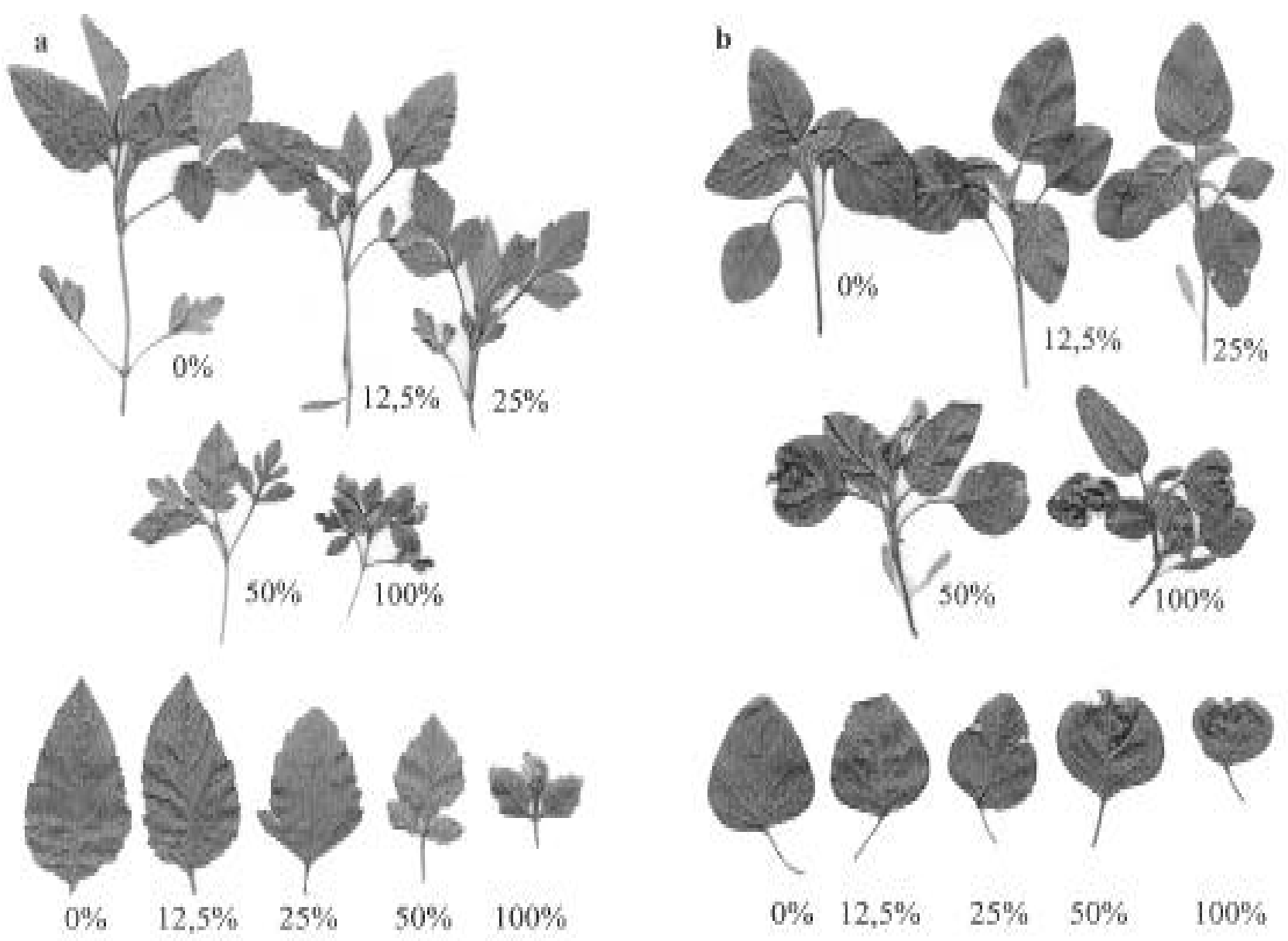

Figura 3 - Fitotoxicidade do extrato de leucena sobre picão preto (a) e caruru (b). Detalhe dos sintomas nas folhas destas plantas daninhas submetidas à concentrações crescentes do extrato.

A aplicação do extrato no solo com plantas daninhas desenvolvidas apresentou menor efeito fitotóxico em relação à aplicação do extrato diretamente nas sementes em papel de filtro. Segundo Almeida (1988) essa divergência de resultados entre os bioensaios é muito comum e é devida essencialmente a variações das concentrações do extrato no solo, que ocorre devido a ação dos microrganismos que degradam os produtos presentes no extrato. De acordo com Rice (1984) e Chou \& Kuo (1986) a persistência da substância e sua interação química com o solo são fatores que também devem ser considerados.

Análise do extrato por HPLC - Na Figura 4 são mostrados os cromatogramas de HPLC em soluções do extrato de leucena com diferentes concentrações da mimosina. A identificação desta substância no extrato, nas concentrações $12,5 \%$ até $100 \%$, corresponderam a uma quantidade de 0,141 a $1,085 \mu \mathrm{g} \mathrm{mL}^{-1}$, mostrando excelente resposta no detetor, com picos bem definidos no tempo de $3,58 \pm 0,03 \mathrm{~min}$. Tais respostas foram associadas ao alto valor do coeficiente de determinação $\left(r^{2}>0,99\right)$, obtido na curva de calibração (curva padrão). O efeito fitotóxico do extrato observado nos bioensaios, provavelmente foi devido ao aleloquímico mimosina, identificado e quantificado pelo HPLC.

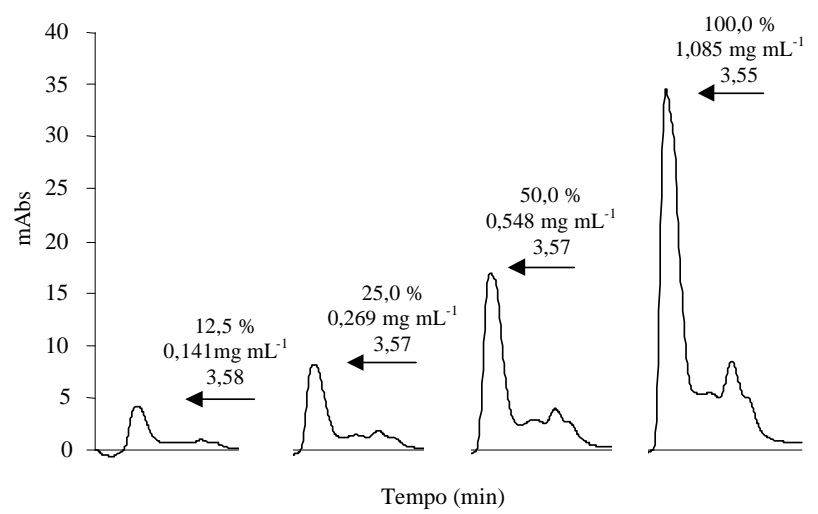

Figura 4 - Cromatogramas de HPLC do extrato de leucena quantificando diferentes concentrações da mimosina.

\section{CONCLUSÕES}

- A aplicação do extrato no papel de filtro apresentou maior efeito fitotóxico sobre as plantas daninhas, em relação à aplicação do extrato no solo.

- O extrato de leucena mostrou maior efeito fitotóxico sobre o picão-preto e caruru, principalmente nas concentrações mais elevadas. 
- A análise cromatográfica indicou grande concentração da substância mimosina em concentrações diretamente proporcionais à concentração do extrato. Acredita-se que a leucena exibe efeito alelopático sobre algumas plantas daninhas e que suas folhas contém uma quantidade substancial de mimosina, a qual mostrou forte atividade fitotóxica nas espécies em estudo.

\section{AGRADECIMENTO}

Ao laboratorista Nilson Machado Lopes do Laboratório de Agroquímica da Embrapa Milho e Sorgo pela valiosa colaboração nas análises cromatográficas por HPLC.

\section{REFERÊNCIAS BIBLIOGRÁFICAS}

ALMEIDA, F.S. A alelopatia e as plantas. Londrina: IAPAR, 1988. 60 p. (Circular, 53).

BUDELMAN, A. The performance of the leaf mulches of Leucaena leucocephala, Flemingia macrophylla and Gliricidia sepium in weed control. Agroforestry Systems, v.6, p.137-145, 1988.

$\mathrm{CHOU}, \mathrm{C} . \mathrm{H}$.; KUO Y.L. Allelopathic research of subtropical vegetation in Taiwan: III. Allelopathic exclusion of understory by Leucaena leucocephala (Lam.) de Wit. Journal of Chemical Ecology, v.12, p.1431-1448, 1986.

CUTLER, H.G. Isolating, characterizing, and screening mycotoxins for herbicidal activity. In: PUTNAM, A.R.; TANG, C.S. (Ed.) The science of allelopathy. New York: John Wiley, 1986. p.147-170.

EI-BEDAWY, T.M; ABD-EL-SAMMAD, A.M.; SAADA, M.Y, ABDEL-FATTAH, S.M. Effect of sodium acetate treatment on metabolism of mimosine and dihydroxy pyridine of Leucaena leaves fed to goats. Egyptian Journal of Nutrition and Feeds, v.2, p.67-77, 1999.

FRANS, R.E. Measuring plant responses. In: WILKINSON, R.E. (Ed.) Research methods in weed science. Australian: Southern Weed Science Society, 1972. p.28-41.
INDERJIT; DAKSHINI, K.M.M. On laboratory bioassays in allelopathy. Botanical Review, v.61, p.28-44, 1995.

JACOBI, U.S.; FERREIRA, A.G. Efeitos alelopáticos de Mimosa bimucronata (DC) OK. sobre espécies cultivadas. Pesquisa Agropecuária Brasileira, v.26, p.935-943, 1991.

KUO, Y.L.; CHOU, C.H.; HU, T.W. Allelopathic potencial of Leucaena leucocephala. Leucaena Research Report, v.3, p.65-70, 1982.

LOWRY, J.B.; TANGENDADJAJA B.; COOK, N.W. Measurement of mimosine and its metabolites in biological materials. Journal of the Science of Food and Agriculture, v.36, p.799-807, 1985.

LOWRY, J.B.; TANGENDADJAJA, M.; TANGENDADJAJA B. Autolysis of mimosine to 3-hydroxy-4-1(H)pyridone in green tissues of Leucaena leucocephala. Journal of the Science of Food and Agriculture, v.34, p.529-533, 1983.

OLIVEIRA JR., R.S.; DELISTOIANOV, F. Profundidade de semeadura e métodos de quebra de dormência afetando a germinação e a emergência de Desmodium purpureum (Mill.) Fawc. et Rend. (Leguminosae-Papilionoideae). Revista Brasileira de Botânica, v.19, p.221-225, 1996.

RICE, E.L. Allelopathy. 2 ed. New York: Academic Press, 1984. 422p.

SKERMAN, P.J. Tropical forage legumes. Rome: FAO, 1977.609p.

SOUZA FILHO, A.P.; RODRIGUES, L.R.A.; RODRIGUES, T.J.D. Efeitos do potencial alelopático de três leguminosas forrageiras sobre três invasoras de pastagens. Pesquisa Agropecuária Brasileira, v.32, p.165-170, 1997.

WARD, K.A.; HARRIS, R.L.N. Inhibition of wool follicle DNA synthesis by mimosine and related $4(1 \mathrm{H})$-pyridones. Australian Journal of Biological Sciences, v.29, p.189-196, 1976.

WEE, K.L.; WANG, S.S. Effect of post-harvest treatment on the degradation of mimosine in Leucaena leucocephala leaves. Journal of the Science of Food and Agriculture, v.39, p.195-201, 1987.

WEIMER, P.J. Manipulating ruminal fermentation: a microbial ecological perspective. Journal of Animal Science, v.76, p.3114-3122, 1998.

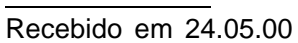

